\title{
PENGARUH GOOD CORPORATE GOVERNANCE DAN BUDAYA TRI HITA KARANA SEBAGAI VARIABEL MODERASI PADA KUALITAS LAPORAN KEUANGAN
}

\author{
Ni Made Vita Indriyani* dan I Wayan Gde Yogiswara Darma Putra \\ Program Studi Akuntansi Fakultas Ekonomi dan Bisnis, Universitas Warmadewa \\ made.vita@yahoo.co.id
}

DiPublikasi: 01/01/2020

http://dx.doi.org/10.22225/kr.11.2.1434.164-169

\begin{abstract}
This research examines the effect of Good Corporate Governance (GCG) and Culture of Tri Hita Karana as a moderating variable on the Quality of Financial Statements with the location of research at a money changer company in Badung Regency. In this research, the analysis technique used is moderated regressions analysis (MRA). The questionnaire returned in this research amounted to $82 \%$. Research respondents included owners, accounting, managers and tellers. Based on the results of the analysis, it was concluded that H1 was accepted. This means that Good Corporate Governance has a positive effect on the quality of financial statements. H2 is also accepted which means THK culture strengthens the influence of Good Corporate Governance on the quality of financial statements.
\end{abstract}

Keywords: Good corporate governance; tri hita karana culture; quality of financial reporting

Abstrak

Penelitian ini menguji pengaruh Good Corporate Governance $(G C G)$ dan Budaya Tri Hita Karana sebagai variabel moderasi pada Kualitas Laporan Keuangan dengan lokasi penelitian pada money changer di Kabupaten Badung. Dalam penelitian ini, teknik analisis yang digunakan adalah moderated regressions analysis (MRA). Kuesioner yang kembali pada penelitian ini berjumlah $82 \%$. Responden penelitian meliputi pemilik, akunting, manajer dan teller. Berdasarkan hasil analisis, disimpulkan bahwa H1 diterima. Hal ini berarti Good Corporate Governance berpengaruh positif signifikan pada kualitas laporan keuangan. $\mathrm{H} 2$ juga diterima yang berarti budaya THK memperkuat pengaruh Good Corporate Governance pada kualitas laporan keuangan.

Kata Kunci: Good corporate governance; budaya tri hita karana; kualitas laporan keuangan

\section{PENDAhuluan}

Mencegah skandal dan penipuan maupun kejahatan dalam perusahaan dapat diminimalisasi dengan Good Corporate Governance (Todorovic, 2013). Good corporate governance juga mampu meyakinkan Prinsipal bahwa akan diberikannya keuntungan oleh para agen dengan tidak menggunakan dana mereka untuk usaha yang merugikan prinsipal (Shleifer \& Vishny, 1997). Ketua Dewan Komisioner Otoritas Jasa Keuangan, Muliaman Hadad menyatakan bahwa adanya penjaminan bisnis yang semakin berkembang serta kelanjutan usaha dengan diterapkannya good corporate governance dalam perusahaan (Afrianto, 2017). Selain good corporate governance, penerapan budaya lokal individu juga sngat diperlukan (Putri, Ulupui, \& Wirawati, 2017). Peranan budaya menjadi perhatian dari para ekonom. Hal ini dikarenakan oleh tidak dapat dipisahkannya interaksi ekonomi dari budaya yang dimiliki oleh berbagai negara di dunia (Sudarma, 2013). Hipotesis budaya sangat penting menjelaskan masalah ekonomi fundamental dengan tujuan bahwa fenomena ekonomi akan mudah dipahami dengan adanya kontibusi budaya (Guiso, Sapienza, \& Zingales, 2008). Pandangan lain dinyatakan oleh (Tabellini, 2008) bahwa pembangunan ekonomi dan studi empiris mengenai budaya merupakan penentu utama dalam literatur keuangan, fenomena pasar modal, dan struktur modal perusahaan (Chui, Lloyd, \& Kwok, 2002) dan pengembangan industri dalam campuran informasi (Huang, 2008), seperti kualitas informasi dalam laporan keuangan.

Kualitas dalam laporan keuangan dicerminkan oleh kualitas informasi yang dipengaruhi dalam membuat keputusan dan didasarkan atas informasi yang dapat dipertanggungjawabkan dan transparan (Payamta, 2006). Peraturan Pemerintah Nomor 71 Tahun 2010 menyebutkan, laporan keuangan akan dihasilkan oleh informasi yang berkualitas dan memiliki kegunaan baik 
dalam jangka pendek maupun panjang untuk mengambil keputusan. Laporan yang memiliki kualitas informasi yang baik, akan menyajikan segala informasi bisnis maupun aktifitas perusahaan secara relevan dan reliabel (Sari \& Suaryana, 2014). Laporan keuangan yang memiliki kualitas yang baik akan memenuhi syarat normatif yaitu relevan, andal, dapat dibandingkan dan dapat dipahami. Hal ini dikarenakan laporan keuangan merupakan bentuk akuntabilitas organisasi untuk pihak yang memiliki kepentingan (Astika \& Yasa, 2018; Karsana \& Suaryana, 2017).

\section{TINJAUAN PUSTAKA}

\section{Stewardship Theory}

Diasumsikan bahwa teori stewardship mencerminkan tindakan manajer atas tanggung jawabnya kepada pihak yang berkepentingan (Donaldson \& Davis, 1991). Teori Stewardship mendorong manajer untuk mengutamakan kepentingan kredibilitas perusahaan dan membuat publik yakin dn percaya atas organisasi. Good steward merupakan gambaran bagi manajer yang dapat mengesampingkan kebutuhan pribadinya (Huse, 2007), dimanatanggung jawab dan tugas yang diberikan pada manajer akan dijalankan dengan baik. Teori stewardship dijadikan dasar untuk mengetahui tanggung jawab manajer atas kualitas dalam laporan keuangan. Manajer perusahaan money changer diharapkan mampu berkomitmen dalam menjalani tugasnya, sehingga pencegahan dalam usaha untuk merugikan perusahaan dapat dihindari.

\section{Pengaruh Good Corporate Governance pada Kualitas Laporan Keuangan}

Secara teoritis, (Sumodiningrat, 1999) menyatakan bahwa good corporate governance adalah upaya sebagai pemimpin yang baik. Secara empiris, (Sahay \& Kumar, 2015) menyatakan bahwa good corporate governance sangat relevan dan penting dilakukan, bahkan hal ini dicantumkan dalam kitab suci di India. Manajer memiliki potensi dan memiliki pengaruh secara signifikan dalam tata kelola perusahaan dengan dampaknya pada kualitas dalam laporan keuangan perusahaan (Cohen, Krishnamoorthy, \& Wright, 2004). Hal ini didukung oleh penelitian (Mulyawan, Wirama, \& Badera, 2017) yang menemukan good corporate governance secara positif mempengaruhi kinerja LPD. Penelitian (Emile, Ragab, \& Kyaw, 2014) mendapatkan hasil bahwa pentingnya praktik good corporate governance bagi perusahaan. Berdasarkan penelitiannya, bahwa good corporate governance mampu membut resiko semakin berkurang, investor semakin tertarik pada perusahaan dan kinerja perusahaan mengalami peningkatan. Selain itu juga, keandalan laporan keuangan juga terpengaruh oleh adanya penerapan good corporate governance (Novatiani \& Fatimmah, 2013).

$\mathrm{H}_{1}$ : Good Corporate Governance berpengaruh positif pada Kualitas Laporan Keuangan

\section{Budaya Tri Hita Karana Memoderasi Pengaruh Good Corporate Governance pada Kualitas Laporan Keuangan}

Secara teoritis, Windia dan Dewi (2007) dalam (Suardikha, 2011) menjelaskan bahwa Tri Hita Karana merupakan tradisi masyarakat Hindu di Bali. Tradisi ini dilaksanakan baik secara kelompok maupun individu dalam kehidupan sehari-hari. Tradisi ini mengedepankan prinsip kebersamaan, kerukunan, dan keseimbangan tercermin dalam tiga dimensi, yaitu parahyangan, pawongan. dan palemahan. Secara empiris, (Kepramareni, Sudarma, Irianto, \& Rahman, 2014) menyatakan bahwa kualitas laporan keuangan dilaksanakan dengan tanggung jawab secara holistik. Hal ini membuktikan bahwa pertanggungjawaban dilakukan dengan memperhatikan hubungannya dengan manusia, lingkungan, dan Tuhan. (Magesh \& Prasad, 2015) menyimpulkan bahwa emosi dan spiritual berjalan seimbang dan hubungan individu dengan organisasi di sekitarnya dapat dibangun. Hubungan yang harmonis ini akan membantu meningkatkan kualitas dalam laporan keuangan dengan adanya integritas pemimpin perusahaan.

$\mathrm{H}_{2}$ : Budaya Tri Hita Karana memperkuat pengaruh good corporate governance pada Kualitas Laporan Keuangan

\section{METODE}

Penelitian ini dilakukan pada perusahaan money changer di Kabupaten Badung dengan menyebarkan kuesioner kepada responden. Responden dalam penelitian ini adalah manajer, accounting, pemilik dan teller. Populasi dalam penelitian ini berjumlah 88 perusahaan. Teknik sampling yang digunakan adalah sampel jenuh atau dikenal dengan istilah sensus, dimana semua anggota populasi dijadikan sampel. Teknik pengumpulan data menggunakan metode survei. 


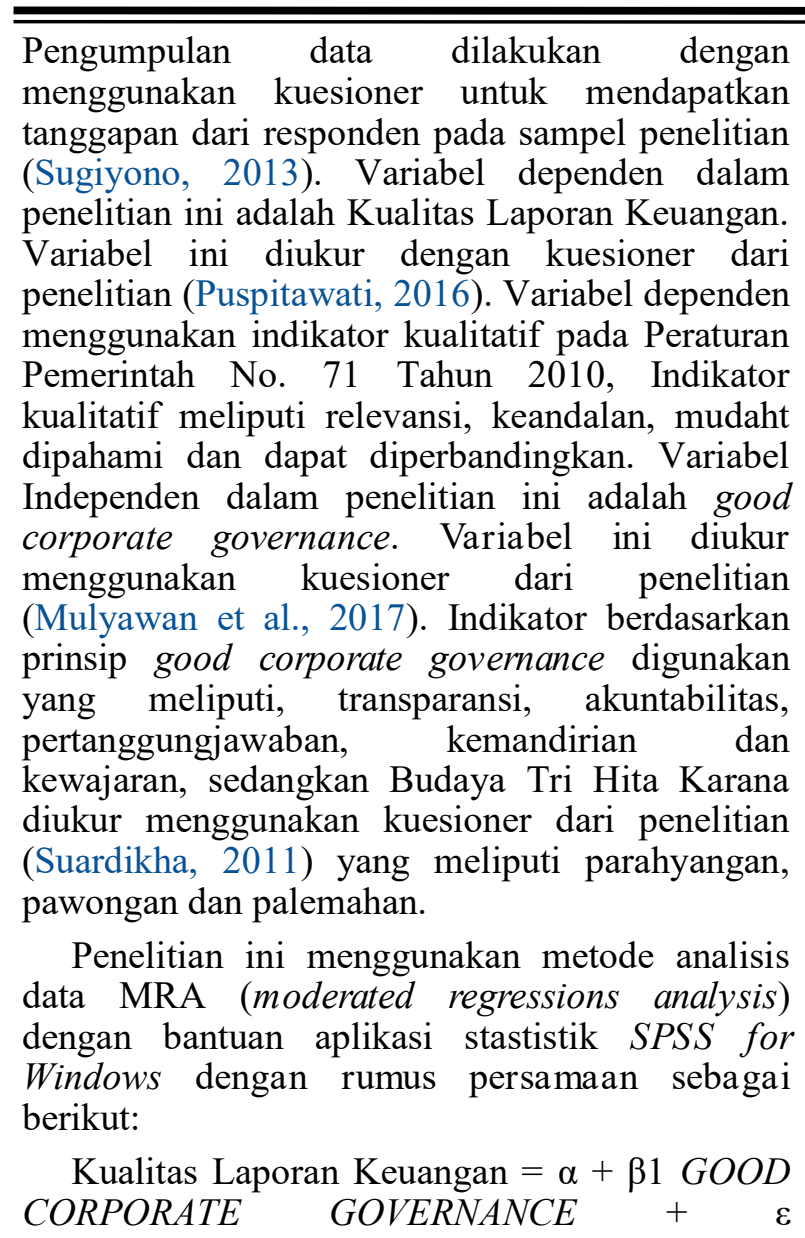

(1)

Kualitas Laporan Keuangan $=\alpha+\beta 1$ GOOD CORPORATE GOVERNANCE + $\beta 2$ THK $+\beta 3$ GOOD CORPORATE GOVERNANCE THK + $\varepsilon$ (2)

$\begin{array}{ll}\alpha & =\text { konstanta } \\ \beta & =\text { Koefisien regresi } \\ \text { GOOD CORPORATE GOVERNANCE } & =\text { Good Corporate Governance } \\ & =\text { Budaya Tri Hita Karana } \\ \text { THK } & =\text { Kesalahan pengganggu }\end{array}$

\section{HASIL DAN PEMBAHASAN}

Penyebaran kuesioner dilakukan pada perusahaan money changer dengan jumlah kuesioner yang disebarkan sebanyak 352. Dari 88 perusahaan yang dijadikan lokasi penelitian, terdapat 4 kuesioner, yang disebarkan pada setiap perusahaan. Kuesioner tersebut didistribusikan kepada pemilik, manajer, accounting dan teller. Berdasarkan kuesioner tersebut, hanya $82 \%$ dari 88 perusahaan yang mengisi kuesioner tersebut, yaitu berjumlah 72 perusahaan, sehingga kuesioner yang kembali sebanyak 288 kuesioner (usability response rate $=82 \%$ ).

Berdasarkan uji validitas, terpenuhinya syarat validitas dari setiap pertanyaan masing-masing variabel. Setiap pertanyaan dari variabel penelitian tersebut memiliki nilai signifikansi kurang dari 0,05. Sedangkan berdasarkan uji reliabilitas menggunakan Cronbach's alpha bahwa seluruh instrumen penelitian dikatakan reliabel, dikarenakan nilai keseluruhan Cronbach's alpha lebih dari 0,60 yang menunjukan hasil yang konsisten akan didapatkan apabila dilakukannya pengukuran kembali atas subjek yang sama pada waktu berbeda.

\section{Hasil Analisis Regresi Linier Sederhana}

Keterangan :

Tabel 1

Hasil Analisis Regresi Linier Sederhana

\begin{tabular}{|c|c|c|c|c|c|c|}
\hline & \multirow[t]{2}{*}{ Moda1 } & \multicolumn{2}{|c|}{ Unst andardized Coefficients } & \multirow{2}{*}{$\begin{array}{c}\begin{array}{c}\text { Standardized } \\
\text { Coefficients }\end{array} \\
\text { Beta } \\
\end{array}$} & \multirow[t]{2}{*}{$t$} & \multirow[t]{2}{*}{$\mathrm{Sig}$} \\
\hline & & $B$ & Std. Error & & & \\
\hline \multirow[b]{2}{*}{1} & (Constant) & 19,557 & 2,123 & \multirow[b]{2}{*}{.574} & 9,213 & \multirow{2}{*}{$\begin{array}{l}.000 \\
.000\end{array}$} \\
\hline & $\begin{array}{l}\text { GOOD CORPORATE } \\
\text { GOVERNANCE }\end{array}$ & .352 & .030 & & 11,869 & \\
\hline & R Square & & & & & .330 \\
\hline & F Statistik & & & & & 140,870 \\
\hline & Signif ikansi & & & & & .000 \\
\hline
\end{tabular}


Berdasarkan hasil analisis regresi linier sederhana (simple regression analyze) seperti yang disajikan pada Tabel 1, maka persamaan strukturalnya adalah sebagai berikut :

$$
\begin{aligned}
& Y_{1}=\alpha+\beta X+e \\
& Y=19,557+0,352 X_{1}+e
\end{aligned}
$$

Keterangan :

Y1 = Kualitas Laporan Keuangan

$\alpha=$ Konstanta

$\beta=$ Koefisien regresi model

$\mathrm{X}=$ Good Corporate Governance

$\mathrm{e}=$ error term model (variabel residual)

Angka-angka tersebut dapat diartikan sebagai berikut:

\section{Konstanta $(\alpha)$}

Memiliki arti apabila semua variabel bebas bernilai nol (0), maka nilai variabel terikat adalah sebesar 19,557. Hal ini menunjukan bahwa ketika GOOD CORPORATE GOVERNANCE tidak diterapkan dengan baik, maka laporan keuangan perusahaan tersebut tidak memiliki kualitas yang baik.

2. Koefisien Regresi Model

Nilai koefisien GOOD CORPORATE GOVERNANCE $\left(\mathrm{X}_{1}\right)$ sebesar 0,352 dan bernilai positif, mengandung arti bahwa setiap peningkatan GOOD CORPORATE GOVERNANCE sebesar 1 satuan maka jumlah persentasi kualitas laporan keuangan akan naik sebesar 0,352 dengan asumsi variabel bebas lainnya dalam model regresi adalah tetap. a. Nilai koefisien determinasi $\left(\mathrm{R}^{2}\right)$

Nilai determinasi total sebesar 0,330 mempunyai arti bahwa sebesar $33 \%$ variasi Kualitas Laporan Keuangan dipengaruhi oleh variasi Good Corporate Governance, sedangkan sisanya sebesar $67 \%$ dijelaskan oleh faktor lain yang tidak dimasukkan ke dalam model.

b. Pengaruh variabel secara parsial (Analisis $t$ -test)

Kriteria pengujian untuk menjelaskan interpretasi pengaruh antar masing-masing variabel sebagai berikut:

Jika Sig. $\mathrm{t}<0.05$ maka $\mathrm{H}_{0}$ ditolak dan $\mathrm{H}_{1}$ diterima.

Jika Sig. $\mathrm{t}>0.05$ maka $\mathrm{H}_{0}$ diterima dan $\mathrm{H}_{1}$ ditolak.

Pengaruh Good Corporate Governance terhadap Kualitas Laporan Keuangan

$\mathrm{H}_{0}$ : Good Corporate Governance tidak berpengaruh signifikan terhadap Kualitas Laporan Keuangan

$\mathrm{H}_{1}$ : Good Corporate Governance berpengaruh signifikan terhadap Kualitas Laporan Keuangan

Berdasarkan hasil analisis pengaruh Good Corporate Governance terhadap Kualitas Laporan Keuangan diperoleh nilai Sig. t sebesar 0,000 dengan nilai koefisien beta 0,352 . Nilai Sig. t $0,000<0,05$ mengindikasikan bahwa $\mathrm{H}_{0}$ ditolak dan $\mathrm{H}_{1}$ diterima. Hasil ini mempunyai arti bahwa Good Corporate Governance berpengaruh signifikan terhadap Kualitas Laporan Keuangan.

Tabel 2

\begin{tabular}{|c|c|c|c|c|}
\hline \multicolumn{5}{|c|}{ Model Summary } \\
\hline Model & $\mathrm{R}$ & R Square & Adjusted R Square & $\begin{array}{l}\text { Std. Error of the } \\
\text { Estimate }\end{array}$ \\
\hline 1 & $.574^{\mathrm{a}}$ &, 330 &, 328 & 5,708096 \\
\hline
\end{tabular}

Hasil Moderated Regressions A nalysis (MRA)

\begin{tabular}{|c|c|c|c|c|}
\hline Model & $\mathrm{R}$ & R Square & Adjusted R Square & $\begin{array}{l}\text { Std. Error of the } \\
\text { Estimate }\end{array}$ \\
\hline 1 &, $682^{\mathrm{a}}$ & 465 & 460 & 5,116520 \\
\hline
\end{tabular}

Model Summary 
Tabel 3

Coefficients

\begin{tabular}{|c|c|c|c|c|c|c|}
\hline \multirow[b]{2}{*}{ Mode } & & \multicolumn{2}{|c|}{ Unstandardized Coefficients } & $\begin{array}{c}\text { Standardized } \\
\text { Coefficients }\end{array}$ & \multirow[b]{2}{*}{$\mathrm{t}$} & \multirow[b]{2}{*}{ Sig. } \\
\hline & & $\mathrm{B}$ & Std. Error & Beta & & \\
\hline \multirow[t]{4}{*}{1} & (Constant) & 72,314 & 9,770 & & 7,402 & ,000 \\
\hline & $\begin{array}{l}\text { GOOD CORPORATE } \\
\text { GOVERNANCE }\end{array}$ &,- 591 &, 142 &,- 964 & $-4,167$ &, 000 \\
\hline & $\begin{array}{l}\text { BUDAYA TRI HITA } \\
\text { KARANA }\end{array}$ & $-1,075$ & ,216 & $-1,118$ & $-4,974$ &, 000 \\
\hline & GCG*THK & ,019 & ,003 & 2,376 & 6,313 &, 000 \\
\hline
\end{tabular}

Berdasarkan model summary, bahwa $\mathrm{R}^{2}$ pada regresi pertama sebesar 0,330 atau $33 \%$, sedangkan setelah ada persamaan regresi kedua dengan nilai $\mathrm{R}^{2}$ mengalami peningkatan menjadi 0,465 atau $46,5 \%$ dapat disimpulkan bahwa dengan adanya Budaya Tri Hita Karana (variabel moderasi) akan dapat memperkuat pengaruh dari Good Corporate Governance pada Kualitas Laporan Keuangan. Hal ini juga dapat dilihat pada Tabel 2, bahwa signifikansi moderasi THK sebesar 0,000 dengan nilai koefisien positif sebesar 0,019 .

\section{SIMPULAN}

Adapun hasil pengujian model regresi dengan analisis regresi linier sederhana (simple regression analyze) untuk mengetahui pengaruh Good Corporate Governance pada Kualitas Laporan Keuangan dan menggunakan MRA untuk mengetahui moderasi dari Budaya THK atas pengaruh dari Good Corporate Governance pada Kualitas Laporan Keuangan tersebut, maka Hasil Pengujian Hipotesis $\left(\mathrm{H}_{1}\right)$ menyatakan bahwa Good Corporate Governance berpengaruh positif terhadap Kualitas Laporan Keuangan perusahaan money changer se-Kabupaten Badung. Tabel 1 menunjukkan nilai signifikansi t $0,000<0,05$ yang mengindikasikan bahwa $\mathrm{H}_{0}$ ditolak dan $\mathrm{H}_{1}$ diterima. Hasil ini mempunyai arti bahwa Good Corporate Governance berpengaruh positif dan signifikan pada Kualitas Laporan Keuangan.

Hasil Pengujian Hipotesis $\left(\mathrm{H}_{2}\right)$ menyatakan bahwa Budaya Tri Hita Karana mampu memperkuat pengaruh dari Good Corporate Governance pada Kualitas Laporan Keuangan perusahaan money changer se-Kabupaten Badung. Tabel 2 menunjukkan nilai signifikansi t $0,000<0,05$ yang mengindikasikan bahwa $\mathrm{H}_{2}$ diterima. Adanya peningkatan $\mathrm{R}^{2}$ pada analisis regresi pertama sebesar 0,330 atau $33 \%$ dan $\mathrm{R}^{2}$ pada analisis regresi kedua sebesar 0,465 atau $46,5 \%$ dengan koefisien positif sebesar 0,019. Hasil ini mempunyai arti bahwa Budaya Tri Hita Karana mampu memperkuat pengaruh Good Corporate Governance pada Kualitas Laporan Keuangan.

\section{DAFTAR PUSTAKA}

Afrianto, D. (2017). Tata Kelola Perusahaan Indonesia Termasuk Peringkat Bawah di Asia Tenggara. Retrieved from https://economy.okezone.com/ $\mathrm{read} / 2017 / 04 / 17 / 278 / 1669893 /$ tata-kelola-perusahaan -indonesia-termasuk-peringkat-bawah-di-asiatenggara

Astika, I. B. P., \& Yasa, G. W. (2018). Kemampuan Komitmen Organisasi Memoderasi Kompetensi Pejabat Penatausahaan Keuangan dan SPI Pada Kualitas Laporan Keuangan Kota Denpasar. EJurnal Akuntansi Universitas Udayana, 22(1), 301325. Retrieved from https://doi.org/10.24843/ EJA.2018.v22.i01.p12

Chui, A. C. W., Lloyd, A. E., \& Kwok, C. C. Y. (2002). The Determination of Capital Structure: Is National Culture a Missing Piece to the Puzzle? Journal of International Business Studies, Palgrave Macmillan; Academy of International Business, 33(1), 99-127. Retrieved from https://ideas.repec.org/a/pal/jintbs/ v33y2002ilp99-127.html

Cohen, J. R., Krishnamoorthy, G., \& Wright, A. (2004). The Corporate Governance Mosaic and Financial Reporting Quality. Journal of Accounting Literature, 87-152. Retrieved from https://papers.ssrn.com/sol3/ papers.cfm?abstract_id=1086743

Donaldson, L., \& Davis, J. H. (1991). Stewardship Theory or Agency Theory: CEO Governance and Shareholder Returns. Australian Journal of Management, 16(1), 49-64. Retrieved from https:// doi.org/10.1177/031289629101600103

Emile, R., Ragab, A., \& Kyaw, S. (2014). The Effect of Corporate Governance on Firm Performance, Evidence from Egypt. A sian Economic and Financial Review, 4(12), 1865-1877. Retrieved from https:// ideas.repec.org/a/asi/aeafrj/2014p1865-1877.html

Guiso, L., Sapienza, P., \& Zingales, L. (2008). Social Capital 
as Good Culture. Journal of the European Economic Association, 6(2-3), 295-320. Retrieved from https://doi.org/10.1162/JEEA.2008.6.2-3.295

Huang, R. R. (2008). Tolerance for uncertainty and the growth of informationally opaque industries. Journal of Development Economics, 87(2), 333-353. Retrieved from https://doi.org/10.1016/ j.jdeveco.2007.10.005

Huse, M. (2007). Board, Governance, and Value Creation: The Human Side of Corporate Governance. Cambridge: Cambridge University Press. Retrieved from https://www.researchgate.net/ publication/230660474_Boards_Governance_and_V alue_Creation_The_Human_Side_of_Corporate_Gov ernance

Karsana, I. W., \& Suaryana, I. G. N. A. (2017). Pengaruh Efektivitas Penerapan Sap, Kompetensi Sdm, Dan Spi Pada Kualitas Laporan Keuangan Pemerintah Kabupaten Bangli. E-Journal Akuntansi Universitas Udayana, 21(1), 643-670. Retrieved from https:// ojs.unud.ac.id/index.php/Akuntansi/article/ view/33664

Kepramareni, P., Sudarma, M., Irianto, G., \& Rahman, A. F. (2014). Sekala and Niskala Accountability practices in the clan-based organization MGPSSR in Bali, Indonesia. Scientific Research Journal (SCIRJ), 2(2), 1-5. Retrieved from http://www.scirj.org/papers0214/scirj-P021497.pdf

Magesh, S., \& Prasad, V. K. (2015). An Approach to Corporate Governance by an Individuals Self Consciousness and Integrated Advancement. Scope International Journal of Science, Humanities, Management and Technology, 1(1), 1-5.

Mulyawan, I. P. A., Wirama, D. G., \& Badera, I. D. N. (2017). Budaya Tri Hita Karana Sebagai Pemoderasi Pengaruh Prinsip Good Corporate Governance Pada Kinerja Lembaga Perkreditan Desa Di Kota Denpasar. Jurnal Ekonomi \& Bisnis Universitas Udayana, 6(8), 3193-3222. Retrieved from https:// doi.org/10.24843/EEB.2017.v06.i08.p10

Novatiani, R. A., \& Fatimmah, J. (2013). Pengaruh Penerapan Good Corporate Governance Terhadap Keandalan Laporan Keuangan (Suvei Pada Tiga Perusahaan BUMN Di Bidang Jasa di Bandung). National Publication Widyatama Repository, 1-19. Retrieved from https://repository.widyatama.ac.id/ xmlui/bitstream/handle/123456789/2227/31.pdf? sequence $=1$

Payamta. (2006). Pengaruh Kualitas Auditor, Indepedensi, dan Opini Audit terhadap Kualitas Laporan Keuangan. Jurnal Bisnis Dan Manajemen, 6(1), 8190.

Puspitawati, D. (2016). Analisis Faktor-Faktor yang Mempengaruhi Kualitas Laporan Keuangan Pemerintah Daerah. Magister Ilmu Akuntansi Fakultas Ekonomi Dan Bisnis Universitas Lampunng Bandar Lampung. Retrieved from http:// digilib.unila.ac.id/25419/3/TESIS TANPA BAB PEMBAHASAN.pdf

Putri, I. G. A. M. A. D., Ulupui, I. G. K. A., \& Wirawati, N. G. P. (2017). Pengaruh Good Corporate Governance dan Budaya Tri Hita Karana Pada Kinerja Bank Perkreditan Rakyat. Jurnal Ilmiah Akuntansi Dan Bisnis Universitas Udayana, 12(1), 17-24. Retrieved from

JIAB.2017.v12.i01.p03

https://doi.org/10.24843/

Sahay, M., \& Kumar, K. (2015). Invigorate corporate board through Indian scriptures. Corporate Ownership \& Control, 12(3), 73-83. Retrieved from http:// doi.org/10.22495/cocv12i3p7

Sari, luh indah novita, \& Suaryana, I. G. N. A. (2014). Pengaruh Kualitas Laporan Keuangan Pada Efisiensi Investasi Perusahaan Pertambangan. E-Journal Akuntansi Universitas Udayana, 8(3), 524-537. Retrieved from https://ojs.unud.ac.id/index.php/ Akuntansi/article/view/8321

Shleifer, A., \& Vishny, R. W. (1997). A Survey of Corporate Governance. Journal of Finance, 52(2), 737-783. Retrieved from https://doi.org/10.1111/j.15406261.1997.tb04820.x

Suardikha, I. M. S. (2011). Pengaruh Budaya Tri Hita Karana(THK) Terhadap Kesuksesan Penggunaan Sistem Informasi Akuntansi (SIA) Studi Pada Bank Perkreditan Rakyat (BPR) di Provinsi Bali. Jurnal Ilmu-Ilmu Sosial (Social Sciences), 23(1), 18-28.

Sudarma, M. (2013). Revealing the Agency Cost, Management Behavior in the Practice of Tri Hita KaranaCulture(A Study At LPDOf Pakraman Village In Denpasar Bali). IOSR Journal of Business and Management (IOSR-JBM), 10(5), 54-61. Retrieved from http://www.iosrjournals.org/iosr-jbm/papers/ Vol10-issue5/H01055461.pdf?id=5054

Sugiyono. (2013). Metode Penelitian Bisnis (Pendekatan Kuantitatif, Kualitatif, dan R\&D). Bandung: Alfabeta.

Sumodiningrat, G. (1999). Pemberdayaan Masyarakat dan Jaringan Pengaman Sosial. Jakarta: PT Gramedia Pustaka Utama.

Tabellini, G. (2008). Institutions and Culture. Journal of the European Economic Association, 6(2-3), 255-294. Retrieved from https://doi.org/10.1162/ JEEA.2008.6.2-3.255

Todorovic, I. (2013). Impact of Corporate Governance on Performance of Companies. Monyenegrin Journal of Economics, 9(2), 47-53. Retrieved from http:// www.mnje.com/sites/mnje.com/files/4754_todorovic.pdf 